\title{
Interação Reprodutor x Rebanho na Produção de Leite da Raça Holandesa no Brasil ${ }^{1}$
}

\section{Cláudio Vieira de Araújo², Robledo de Almeida Torres ${ }^{3}$, Cláudio Nápolis Costa ${ }^{4}$, Paulo Sávio Lopes $^{3}$, Carmen Silva Pereira ${ }^{3}$, Ricardo Frederico Euclydes ${ }^{3}$, Rodolpho de Almeida Torres Filho ${ }^{2}$}

RESUMO - Registros de produção de leite de vacas da raça Holandesa foram utilizados na verificação da efetividade da inclusão da interação reprodutor x rebanho no modelo estatístico para estimação de componentes de variâncias, como uma forma de ajustamento para heterogeneidade de variância entre rebanhos. Com base no desvio-padrão fenotípico da produção de leite, ajustada a 305 dias de lactação e à idade adulta da vaca, os rebanhos foram estratificados em três classes: alto (>1375 kg), médio (1165 a $1375 \mathrm{~kg}$ ) e baixo (<1165 kg) desvios-padrão fenotípicos. Componentes de variância em análise de características múltiplas, em que se considerou a produção de leite ajustada a 305 dias de lactação e à idade adulta em cada classe de desvio-padrão fenotípico como característica diferente, foram estimados pela máxima verossimilhança restrita, utilizando-se dois modelos animais que diferiam apenas na ausência e na presença da interação reprodutor x rebanho. $\mathrm{O}$ teste da razão de verossimilhança foi utilizado na verificação da efetividade da inclusão da interação no modelo. As médias e os componentes de variância para a produção de leite, de modo geral, aumentaram da classe de baixo para a classe de alto desvio-padrão fenotípico. As estimativas de componentes de variância, obtidas pelo modelo que incluía a interação reprodutor x rebanho, foram ligeiramente menores do que as dos modelos sem interação, exceto na variância residual, cujas estimativas, nos dois modelos, foram bastante próximas. As estimativas de herdabilidade para a produção de leite ajustada a 305 dias de lactação e à idade adulta, obtidas pelos dois modelos para uma mesma classe de desvio-padrão foram próximas, oscilando de 0,251 a 0,362 e de 0,244 a 0,342, para os modelos sem e com a interação reprodutor x rebanho, respectivamente. As correlações genéticas, para produção de leite, entre as classes de desvios-padrão fenotípicos foram todas próximas da unidade. As proporções da variância fenotípica da produção de leite, devido à variância da interação reprodutor x rebanho, oscilaram de 2,2 a 4,4\%, e o logaritmo natural da função de verossimilhança aumentou significativamente, quando se incluiu a interação reprodutor x rebanho no modelo.

Palavras-chave: componentes de variância, interação reprodutor x rebanho, produção de leite

\section{Sire-By-Herd Interaction for Milk Yield of Holstein Cows in Brazil}

\begin{abstract}
Milk yield adjusted for 305 days and for age of Holtein cows were used to verify the effectiveness of including sire-by-herd interaction in the model of analysis as an adjustment factor for heterogeneous variances between herds. The herds were classified in three classes of phenotypic standard deviation: high, medium and low. Variance component estimates were obtained by Restricted Maximum Likelihood methodology, for classes of phenotypic standard deviation, considering each one as a different trait, using a multiple trait analysis. Two different animal models were used, either fitting or not fitting sire-by-herd interaction effect.The effectiveness of including this interation in the model was tested by Likelihood ratio test. Averages and variance components for milk yield increased from low to high phenotypic standard deviation classes. Variance component estimates were smaller, when sireby-herd interaction was fitted, however, residual variance components were similar for both models. Heritability estimates for milk yield obtained by fitting or not fitting the interaction term in the model, were similar. Genetic correlation between classes of phenotypic standard deviation were close to unity. The proportion of the phenotypic variance due to sire-by-herd interaction variance fluctuated from 2.2 to 4.4 percent. The logarithms of the likelihood functions were higher when fitting a sire-by-herd interaction than for the model not including the interaction, for all classes.
\end{abstract}

Key Words: variance components, sire by herd interaction, milk yield

\section{Introdução}

A expressão fenotípica do genótipo requer ação do ambiente, ao passo que qualquer influência do ambiente só pode ser medida quando há alteração na expressão do genótipo. Assim, variações genéticas e de ambientes influenciamodesempenhodoanimal(DICKERSON,1962).
A interação genótipo $\mathrm{x}$ ambiente implica que o melhor genótipo em um ambiente poderia não o ser em outro; como exemplo, uma raça com alta produção de leite em clima temperado, pode não apresentar a mesma superioridade em clima tropical (FALCONER, 1989).

PACKER (1985) relatou que a expressão fenotípica de determinado animal, submetido a um

\footnotetext{
1 Parte da Dissertação de Mestrado em Zootecnia do primeiro autor, apresentada à UFV, financiado pela CAPES.

2 Estudante de Pós-graduação do DZO-UFV. E.mail: cvaraujo@alunos.ufv.br

3 Professor da Universidade Federal de Viçosa-Depto de Zootecnia, 36570-000, Viçosa - MG.

4 Pesquisador Embrapa Gado de Leite, Rua Eugênio do Nascimento, 610, 36038-330, Juiz de Fora - MG.
} 
ambiente específico, seria conseqüência, além dos genes responsáveis pela expressão da característica, da ação de genes relacionados com a adaptação do animal ao ambiente ao qual este está submetido. A expressão fenotípica dos genes ligados diretamente à expressão da característica poderia ficar comprometida quando ocorressem alterações nas condições de ambiente, em razão da ausência da expressão de alelos de genes responsáveis pela adaptabilidade do animal ao novo ambiente.

STANTON et al. (1991) apresentaram duas situações em que diferenças nas respostas à seleção seriam verificadas em ambientes diferentes, caracterizando a interação genótipo $\mathrm{x}$ ambiente. A primeira situação seria atribuída a casos em que bases genéticas diferentes estariam atuando em diferentes ambientes; nesse caso, a correlação genética entre a expressão fenotípica nos dois ambientes seria, substancialmente, menor que 1,0. Outra situação que caracteriza a interação genótipo $\mathrm{x}$ ambiente seria resultante da heterogeneidade de variância genética e ambiental, como no caso das avaliações de características simples, em que os reprodutores teriam a mesma classificação em cada ambiente, mas as diferenças na resposta à seleção das filhas e nos valores genéticos dos touros seriam menores no ambiente com menor variabilidade.

A semelhança entre filhas de um touro em um mesmo rebanho reflete tanto a interação genótipo $\mathrm{x}$ ambiente como a covariância ambiental entre o desempenho de meio-irmãs paternas, companheiras de rebanho (MEYER, 1987; BANOS e SHOOK, 1990; e COSTA, 1999). BERESKIN e LUSH (1965), NORMAN (1974) e MEYER (1987) relataram que a covariância ambiental entre meio-irmãs paternas tem origem em fatores biológicos, de manejo e estatísticos, como falha na remoção do efeito de rebanho, de ano-estação de parto da vaca ou de algum outro fator fixo, resultando em um modelo inadequado à avaliação genética. Fatores de ajustamento para efeitos fixos também podem ser inapropriados a rebanhos com manejo específicos. O tratamento diferenciado dado a filhas de um mesmo reprodutor também causa correlação ambiental entre meio-irmãs paternas, visto que filhas de determinado reprodutor são submetidas a um ambiente mais favorável, o que provoca superestimação dos seus valores genéticos.

A interação reprodutor $\mathrm{x}$ rebanho pode ser observada quando diferenças entre progênies de um mesmo reprodutor não são as mesmas em diferentes rebanhos, sendo a heterogeneidade de variância responsável por parte destas.
Variâncias heterogêneas entre rebanhos e aumento da variância, de acordo com o aumento dos níveis de produção dos rebanhos, regiões ou países, têm sido verificados por vários autores, como HILL et al.(1983); MEYER (1987); BOLDMAN e FREMAN (1990); DONG e MAO (1990); STANTON et al. (1991); DODENHOF e SWALVE (1997); COSTA (1998); TORRES (1998); e ENGHEL et al. (1999).

Quando a heterogeneidade de variância é desprezada, embora esteja presente, a produção das filhas de determinado reprodutor será ponderada na proporção dos desvios-padrão dos rebanhos nos quais essas filhas foram criadas. O resultado é que as produções das filhas, oriundas de rebanhos com maiores variâncias, influenciarão mais a avaliação de reprodutores do que a de filhas oriundas de rebanhos com menores variâncias. No caso de as filhas dos diversos reprodutores serem distribuídas, uniformemente, entre os rebanhos com variação diferente, nenhum vício seria observado. Entretanto, se as estimativas de herdabilidades também diferissem entre os rebanhos, a acurácia das avaliações genéticas dos animais seria reduzida, em razão de não serem consideradas essas diferenças (TORRES, 1998).

Ao analisar dados de primeira lactação de novilhas de diferentes grupos genéticos da raça Holandesa, MEYER (1987) considerou os conceitos de interação reprodutor $\mathrm{x}$ rebanho e de covariância ambiental comum a todas as filhas de um reprodutor em um rebanho, como estatisticamente equivalentes. Ao utilizar três modelos de reprodutor, em que o primeiro não considerava nenhum efeito de interação, o segundo considerava o efeito da interação reprodutor $\mathrm{x}$ rebanho e o terceiro modelo considerava o efeito da interação reprodutor x rebano-ano-estação de parto. A autora verificou que com este último modelo, a interação obteve maior proporção da variância fenotípica em relação ao modelo que incluía a interação reprodutor $x$ rebanho, sugerindo que em procedimentos de avaliações genéticas de reprodutores, ao ignorar-se a covariância ambiental entre vacas na mesma subclasse, a confiabilidade das provas dos reprodutores poderia ser superestimada e que avaliações genéticas de reprodutores, baseadas em registros de filhas em poucos rebanhos, deveriam ser consideradas com cautela.

MRODE et al. (1994) utilizaram dados de produção de leite, gordura e proteína no Reino Unido, referentes às primeiras cinco lactações de 40.066 registros de vacas da raça Holandesa, 17.674 registros de vacas da raça Shorthorn, 7.245 registros de 
994 Rev. bras. zootec.

vacas da raça Jersey, 19.994 registros de vacas da raça Ayrshire e 16.850 registros de vacas da raça Guernsey. Ao utilizarem o modelo animal, verificaram que a proporção da variação total da produção de leite, resultante do componente de variância referente à interação reprodutor $\mathrm{x}$ rebanho, variou de 0,024 a 0,063 e de 0,02 a 0,04 , nas primeiras e em todas as lactações, respectivamente. Esses autores concluíram que a interação reprodutor $x$ rebanho é importante e deve ser considerada na avaliação genética de reprodutores para minimizar vícios.

COSTA (1999), em trabalho de revisão, reportou que a estimativa da variância, referente à interação reprodutor $\mathrm{x}$ rebanho, tem representado cerca de $1 \mathrm{a}$ $4 \%$ da variação total da produção de leite.

Este estudo objetivou estimar componentes de variância para a produção de leite referente ao efeito da interação reprodutor $x$ rebanho e verificar a influencia da inclusão desta interação no modelo de análise, como fator de ajustamento para a heterogeneidade de variâncias ambiental em bovinos da raça Holandesa no Brasil.

\section{Material e Métodos}

Os dados utilizados são provenientes do Controle Leiteiro da Associação Brasileira de Criadores da Raça Holandesa e de suas filiadas e compõem o arquivo Zootécnico Nacional de Gadode Leite, sob gerenciamento do Centro Nacional de Pesquisa em Gado de Leite, da Empresa Brasileira de Pesquisa Agropecuária (CNPGLEMBRAPA), conforme convênio com o Ministério da Agricultura, com lactações nos anos de 1980 a 1993.

Os dados foram editados para eliminação de registros incompletos, lactações encerradas por causas anormais, lactações inferiores a 150 e superiores a 450 dias, e registros de produção de leite inferiores a $1.000 \mathrm{~kg}$ ou superiores a $15.000 \mathrm{~kg}$. Os meses de parto das vacas foram agrupados em duas épocas de parto da vaca, como época 1 , de abril a setembro, e época 2 , que corresponde aos meses de outubro a março. Posteriormente, os efeitos fixos de rebanho, ano e época de parto da vaca foram agrupados em classes. Com referência à informação sobre ascendência e origem das vacas, classificaram-se os animais em Grupo 1, Holandês puro de origem, e Grupo 2, Holandês puro por cruzamento, composto de animais com composição genética igual ou superior a 31/32 da raça Holandesa.

Nas análises de variância, os dados foram previamente ajustados para duração da lactação e para as classes ordem-idade da vaca ao parto, por meio de fatores de ajustamento estimados nos próprios dados.

Os rebanhos foram classificados em três classes de desvio-padrão fenotípico para produção de leite ajustada a 305 dias de lactação e à idade adulta da vaca, com base no número de registros de produção de leite. As classes de desvios-padrão fenotípico foram dispostas da seguinte forma: 1) Baixo desvio-padrão: classe formada por rebanhos que apresentavam desvios-padrão fenotípicos inferiores a $1.165 \mathrm{~kg}$; 2) Médio desvio-padrão: referente a rebanhos que apresentavam desvios-padrão maiores ou iguais a $1.165 \mathrm{~kg}$ e inferiores a $1375 \mathrm{~kg}$; e 3) Alto desvio-padrão: nesta classe estão englobados todos os rebanhos com desvios-padrão fenotípico iguais ou superiores a $1375 \mathrm{~kg}$.

Em edições adicionais impôs-se a restrição de que, no mínimo, cada classe de rebanho-ano-época de parto possuísse quatro observações e cada reprodutor possuísse três filhas em dois diferentes rebanhos e filhas nas três classes de desvio-padrão fenotípico, resultando em 53.937 lactações de 27.480 vacas, filhas de 272 reprodutores.

O modelo para características múltiplas para a análise de obtenção de componentes de variância para produção de leite ajustada a 305 dias de lactação e à idade adulta da vaca, considerando a produção de leite em cada classe de desvio-padrão fenotípico como característica diferente e incluindo o efeito da interação reprodutor x rebanho no modelo, foi o seguinte:

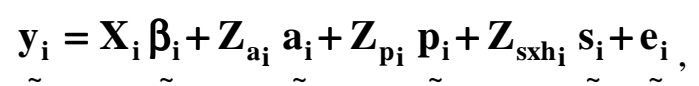

em que: $\mathbf{y}_{\mathbf{i}}=$ vetor ni $\mathrm{x} 1$, de ni observações de produção de leite na classe de desvio-padrão i ( $\mathrm{i}=$ baixo, médio, alto); $\mathbf{X}_{\mathbf{i}}=$ matriz nix $\mathrm{f}$, de incidência de $\mathrm{f}$ níveis dos efeitos fixos na classe de desviopadrão i; $\underset{\sim}{\boldsymbol{\beta}_{\mathbf{i}}}=$ vetor $\mathrm{f}$ x 1 , de efeitos fixos da classe $\mathrm{i}$; $\mathbf{Z}_{\mathbf{a i}}=$ matriz diagonal ni $\times \mathrm{Ni}$, de incidência dos valores genéticos, contendo 1 na classe $\mathrm{i} ; \mathbf{a}_{\mathbf{i}}=$ vetor Ni x 1, de valores genéticos dos animais da classe $i$; $\mathbf{Z}_{\mathbf{p i}}=$ matriz diagonal ni $\mathrm{x} \mathrm{Ni}$, de incidência dos efeitos permanentes de meio ambiente dos animais, na classe $\mathrm{i}$; $\mathbf{p}_{\mathbf{i}}=$ vetor $\mathrm{Ni} \times 1$, de valores referentes ao efeito permanente de meio ambiente dos animais da classe $i$; e $\mathbf{Z}_{\text {sxhi }}$ matriz de incidência de dimensão nxh, referente aos efeitos da interação reprodutor $\mathrm{x}$ rebanho, na classe $\mathrm{i} ; \mathbf{s}_{\mathbf{i}}=$ vetor de dimensão $\mathrm{hx} 1$, ou seja, igual ao número de níveis de interação reprodutor $x$ rebanho da classe $i$; $\mathbf{e}_{\mathbf{i}}=$ vetor de resíduos da mesma dimensão de $\mathrm{y}_{\mathrm{i}}$.

Levando-se em conta uma distribuição conjunta 
das características, da seguinte forma:

$$
\begin{aligned}
& \mathbf{y}=\left[\begin{array}{c}
\mathbf{y}_{1} \\
\tilde{y_{2}} \\
\tilde{y_{3}} \\
\tilde{\sim}
\end{array}\right], \quad \mathbf{X}=\left[\begin{array}{ccc}
\mathbf{x}_{1} & 0 & 0 \\
0 & \mathbf{x}_{2} & 0 \\
0 & 0 & \mathbf{x}_{3}
\end{array}\right], \quad \underline{\beta}=\left[\begin{array}{c}
\beta_{1} \\
\tilde{\beta_{2}} \\
\tilde{\beta_{3}} \\
\sim
\end{array}\right] \\
& \mathbf{Z}_{\mathrm{a}}=\left[\begin{array}{ccc}
\mathbf{Z}_{\mathrm{a} 1} & \mathbf{0} & \mathbf{0} \\
\mathbf{0} & \mathbf{Z}_{\mathrm{a} 2} & \mathbf{0} \\
\mathbf{0} & \mathbf{0} & \mathbf{Z}_{\mathrm{a} 3}
\end{array}\right], \mathbf{Z}_{\mathrm{p}}=\left[\begin{array}{ccc}
\mathbf{Z}_{\mathrm{p} 1} & \mathbf{0} & \mathbf{0} \\
\mathbf{0} & \mathbf{Z}_{\mathrm{p} 2} & \mathbf{0} \\
\mathbf{0} & \mathbf{0} & \mathbf{Z}_{\mathrm{p} 3}
\end{array}\right], \mathbf{Z}_{\mathrm{sxh}}=\left[\begin{array}{ccc}
\mathbf{Z}_{\mathrm{sxh1}} & \mathbf{0} & \mathbf{0} \\
\mathbf{0} & \mathbf{Z}_{\mathrm{sxh} 2} & \mathbf{0} \\
\mathbf{0} & \mathbf{0} & \mathbf{Z}_{\mathrm{sxh} 3}
\end{array}\right] \\
& \underset{\sim}{\mathbf{a}}=\left[\begin{array}{c}
\mathbf{a}_{1} \\
\tilde{a_{2}} \\
\tilde{a_{3}} \\
\tilde{\sim}
\end{array}\right], \quad \underline{p}=\left[\begin{array}{c}
p_{1} \\
\tilde{p_{2}} \\
\tilde{p_{3}} \\
\sim
\end{array}\right], \quad \underline{s}=\left[\begin{array}{c}
s_{1} \\
\tilde{s} \\
\tilde{s} \\
s_{3} \\
\sim
\end{array}\right] \quad \mathbf{e}=\left[\begin{array}{c}
\mathbf{e}_{1} \\
\tilde{e_{2}} \\
\tilde{e_{3}} \\
\tilde{r}
\end{array}\right]
\end{aligned}
$$

em que: $\mathrm{y}_{\sim}=$ produção de leite na classe de desviopadrão fenotípico baixo; $\mathrm{y}_{2}=$ produção de leite na classe de desvio-padrão fenotípico médio; e $\mathrm{y}_{3}=$ produção de leite na classe de desvio-padrão fenotípico alto.

Admitindo-se que $\mathbf{y}, \mathbf{a}, \mathbf{p}, \mathrm{s}$ e e tenham distribuição normal multivariãa, as esperanças e variâncias são assumidas como:

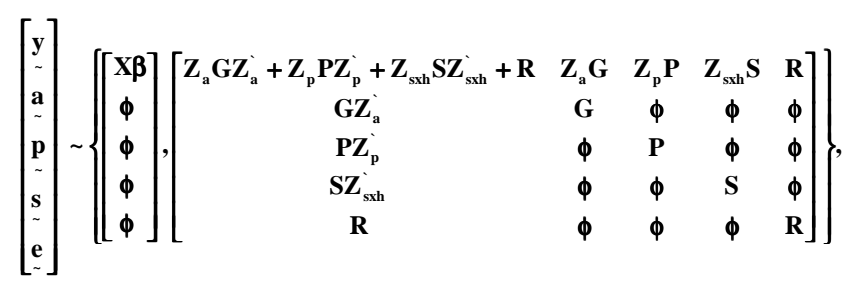

tem-se que:

$$
\begin{aligned}
& \mathbf{G}=\mathbf{A} \otimes \mathbf{G}_{0}, \\
& \mathbf{P}=\mathbf{I}_{\mathrm{N}} \otimes \mathbf{P}_{\mathbf{0}}, \\
& \mathbf{S}=\mathbf{I}_{\mathrm{h}} \otimes \mathbf{S}_{\mathbf{0}}, \mathrm{e} \\
& \mathbf{R}=\mathbf{I}_{\mathbf{n}} \otimes \mathbf{R}_{\mathbf{0}},
\end{aligned}
$$

em que: $\mathbf{A}=$ matriz de numerador do coeficiente de parentesco entre os indivíduos, de ordem igual ao número total de indivíduos $(\mathrm{N}) ; \mathbf{G}_{\mathbf{o}}=$ matriz q x q, de variância e covariância genética aditiva entre as q características; e $\otimes=$ operador produto direto (SEARLE, 1966).

$$
\mathbf{G}_{0}=\left[\begin{array}{lll}
\sigma_{\mathrm{a} 11}^{2} & \sigma_{\mathrm{a} 12} & \sigma_{\mathrm{a} 13} \\
\sigma_{\mathrm{a} 21} & \sigma_{\mathrm{a} 22}^{2} & \sigma_{\mathrm{a} 23} \\
\sigma_{\mathrm{a} 31} & \sigma_{\mathrm{a} 32} & \sigma_{\mathrm{a} 33}^{2}
\end{array}\right],
$$

em que: $\boldsymbol{\sigma}^{\mathbf{2}}$ aii $=$ variância genética aditiva da caracterís-

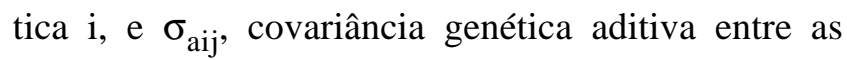
características i e j; $\mathbf{I}_{\mathbf{N}}=$ matriz identidade, de $\operatorname{ordem} \mathrm{N}$; e sendo:

$$
P_{0}=\left[\begin{array}{ccc}
\sigma_{\mathrm{p} 11}^{2} & 0 & 0 \\
0 & \sigma_{\mathrm{p} 22}^{2} & 0 \\
0 & 0 & \sigma_{\mathrm{p} 33}^{2}
\end{array}\right]
$$

em que: $\boldsymbol{\sigma}_{\text {pii }}^{2}=$ é a variância referente ao efeito permanente de meio ambiente da vaca na característica $\mathrm{i} ; \mathbf{I}_{\mathbf{h}}=$ é uma matriz identidade, de ordem $\mathrm{h}$, ou seja, igual ao número de níveis do efeito da interação reprodutor $\mathrm{x}$ rebanho, na característica $\mathrm{i}$, e

$$
\mathbf{s}_{0}=\left[\begin{array}{ccc}
\sigma_{\mathrm{sxh} 11}^{2} & 0 & 0 \\
0 & \sigma_{\mathrm{sxh} 22}^{2} & 0 \\
0 & 0 & \sigma_{\mathrm{sxh} 33}^{2}
\end{array}\right]
$$

em que: $\boldsymbol{\sigma}_{\text {sxhii }}^{\mathbf{2}}=$ é a variância referente a interação reprodutor $\mathrm{x}$ rebanho, para a característica $\mathrm{i}$; $\mathbf{I}_{\mathbf{n}}=$ matriz identidade, de ordem $\mathrm{n} ; \mathrm{e}$

$$
\mathbf{R}_{0}=\left[\begin{array}{ccc}
\sigma_{\mathrm{e} 11}^{2} & \mathbf{0} & \mathbf{0} \\
\mathbf{0} & \sigma_{\mathrm{e} 22}^{2} & 0 \\
\mathbf{0} & \mathbf{0} & \sigma_{\mathrm{e} 33}^{2}
\end{array}\right],
$$

em que: $\boldsymbol{\sigma}^{2}$ eii $=$ a variância residual da característica $i$.

A análise que visa à obtenção de componentes de variância e que considera a produção de leite ajustada a 305 dias de lactação e à idade de cada classe de desvio-padrão fenotípico como uma característica diferente, sem levar em conta o efeito da interação reprodutor $\mathrm{x}$ rebanho, foi obtida de um modelo semelhante ao (1.1), sem considerar-se, no entanto, a inclusão da matriz $\mathbf{Z}_{\mathbf{s x h i}}$ e do vetor $\mathbf{s}_{\mathbf{i}}$.

Todas as estimativas de componentes de (co)variâncias e dos parâmetros genéticos foram obtidas por meio do programa MTDFREML (Multiple Trait Derivative Free Restricted Maximum Likelihood), descrito por BOLDMAN et al. (1995), que utiliza a metodologia de máxima verossimilhança restrita livre de derivadas. $\mathrm{O}$ critério adotado na convergência da variância dos valores do simplex foi de, no mínimo, $10^{-9}$.

Para determinar a importância da inclusão do efeito da interação reprodutor $\mathrm{x}$ rebanho no modelo utilizou-se o teste da razão de verossimilhança de modelos seqüencialmente reduzidos (RAO, 1973).

\section{Resultados e Discussão}

As médias observadas, os desvios-padrão, número de lactações, número de classes de rebanho-anoestação, de rebanhos e distribuição das lactações por 
ordem de parto para produção de leite ajustada a 305 dias de lactação e à idade adulta, em cada classe de desvio-padrão fenotípico são apresentados na Tabela 1. As médias da produção de leite aumentaram da classe de baixo desvio-padrão fenotípico para a classe de alto desvio-padrão fenotípico.

As estimativas de componentes de (co)variância referentes aos efeitos genético aditivo, permanente de meio, interação reprodutor x rebanho e residual, para produção de leite ajustada a 305 dias de lactação e à idade adulta, podem ser observadas nas Tabelas 2 e 3. Os componentes de variância aumentaram da classe de baixo desvio-padrão fenotípico para a classe de alto desvio-padrão fenotípico, com exceção dos componentes de variância referentes ao efeito permanente de meio, que foram maiores na classe de desviopadrão fenotípico médio. Os componentes de variância, obtidos pelo modelo que incluiu a interação reprodutor $\mathrm{x}$ rebanho, apresentaram ligeiras reduções nas variâncias genética aditiva e permanente de meio. Praticamente não houve alterações do componente de variância residual quando no modelo foi ajustado o termo de interação. Aumento nas estimativas dos componentes de variância genética e residual, com aumento do nível de produção dos rebanhos, foi também observado por DE VEER e VAN VLECK (1987), BOLDMAN E FREEMAN (1990), DONG e MAO (1990), SHORT et al. (1990), COSTA (1998) e TORRES (1998).

Tabela 1 - Médias e desvios-padrão (D.P.) da produção de leite ajustada para 305 dias de lactação e idade adulta, número de lactações, de classes de rebanho-ano-estação (RAE), de rebanhos (REB) e de lactações por ordem de parto (OP), conforme classes de desvio-padrão

Table 1 - Means and standard deviations (D.P.) for 305 days mature equivalent milk yield, number of lactations, number of classes of herd-year-season (RAE), number of herds (REB) and distribuition of the lactations per parity $(O P)$ by standard deviation class

\begin{tabular}{lccc}
\hline Parâmetros & \multicolumn{3}{c}{$\begin{array}{c}\text { Classes de devios-padrão } \\
\text { Parameters }\end{array}$} \\
\cline { 2 - 4 } & $\begin{array}{c}\text { Alto } \\
\text { Hight }\end{array}$ & $\begin{array}{c}\text { Médio } \\
\text { Average }\end{array}$ & $\begin{array}{c}\text { Baixo } \\
\text { Low }\end{array}$ \\
\hline Médias (kg) & $7.260,00$ & $7.012,10$ & $6.330,50$ \\
Means & & & \\
D.P. (kg) & $1.728,24$ & $1.451,33$ & $1.379,03$ \\
No de lactações & 14.758 & 20.132 & 19.047 \\
Number of lactations & & & \\
RAE & 1335 & 1387 & 1280 \\
REB & 262 & 135 & 140 \\
OP $=1$ & 6720 & 8698 & 8134 \\
OP $=2$ & 3382 & 4858 & 4560 \\
OP $\geq 3$ & 4656 & 6576 & 6353 \\
\hline
\end{tabular}

As estimativas de herdabilidade e a proporção da variação total em razão das variâncias dos efeitos permanente de meio e ambiental, obtidas pelos modelos com e sem interação, são próximas, conforme pode ser observado na Tabela 4 . Devido ao aumento nas estimativas de herdabilidade da classe de baixo para alto desvio padrão fenotípico e com a proporção da variância total em razão da variância ambiental em cada classe de desvio padrão próximas entre sí, acredita-se que grande parte da heterogeneidade de variância da produção de leite teria a sua origem em fatores genéticos. Embora a presença da interação reprodutor $x$ rebanho no modelo não tenha alterado as estimativas de herdabilidade, observa-se aumento significativo da função de verossimilhança, ao considerar essa interação no modelo, pois o valor encontrado para o teste de razão de verossimilhança foi de 72,35 ( $\mathrm{P}<0,01)$. MEYER (1987) encontrou valores da , proporção da variância fenotípica na produção de leite devido à interação reprodutor $x$ rebanho, entre grupos de rebanhos, variando de 3,35 a $3,87 \%$, e valores de 2,22 a 3,00\%, quando se ajustou à interação reprodutor x rebanho. BANOS e SHOOK (1990) verificaram que a proporção da variância total da produção de leite, devido à interação reprodutor $\mathrm{x}$ rebanho, variou de 1,31 a 7,33\%.

As correlações genéticas, para produção de leite ajustada para 305 dias de lactação e idade adulta, entre as classes de desvios-padrão, foram próximas da unidade (Tabela 4), o que indica que os reprodutores seriam classificados de forma similar independentemente se a informação de suas filhas fossem provenientes de rebanhos envolvidos em sistemas de alta ou baixa produtividade.

Com base nas estimativas de componentes de (co)variância genética aditiva da produção de leite ajustada para 305 dias e idade adulta, obtidas em análise de característica múltipla, foram calculados os coeficientes de regressão genética das características, medidas nas classes de médio e baixo desviospadrão fenotípicos, em razão da classe de alto desviopadrão fenotípico ( $\mathrm{b}_{\mathrm{AM}} \mathrm{e} \mathrm{b}_{\mathrm{AB}}$, respectivamente). Os valores calculados foram $\mathrm{b}_{\mathrm{AM}}=0,666 \mathrm{e} \mathrm{b}_{\mathrm{AB}}=0,588$, para as estimativas obtidas por meio do modelo sem $\mathrm{o}$ termo de interação reprodutor $\mathrm{x}$ rebanho, $\mathrm{e}$ $\mathrm{b}_{\mathrm{AM}}=0,687 \mathrm{eb}_{\mathrm{AB}}=0,623$, para as estimativas obtidas pelo modelo com o termo de interação. Esses valores representam o ganho genético esperado nos rebanhos de médio e baixo desvios-padrão, por unidade de ganho genético obtido nos rebanhos de alto desvio-padrão, e maiores ganhos seriam esperados 
Tabela 2 - Estimativas de componentes de (co)variância genética aditiva, permanente de meio, e residual, para produção de leite ajustada a 305 dias e idade adulta, obtidas pelos modelos sem interação

Table 2 - Additive genetic, permanent environment and residual variance components for 305 days mature equivalent milk yield in a model without sire by herd interaction

\begin{tabular}{|c|c|c|c|}
\hline \multirow[t]{2}{*}{$\begin{array}{l}\text { Componente } \\
\text { Component }\end{array}$} & \multicolumn{3}{|c|}{$\begin{array}{l}\text { Classes de devios-padrão } \\
\text { Standard deviation class }\end{array}$} \\
\hline & $\begin{array}{l}\text { Alto } \\
\text { Hight }\end{array}$ & $\begin{array}{l}\text { Médio } \\
\text { Average }\end{array}$ & $\begin{array}{l}\text { Baixo } \\
\text { Low }\end{array}$ \\
\hline $\begin{array}{l}\text { (Co) variância genética aditiva }\left(\mathrm{kg}^{2}\right) \\
(\text { Co }) \text { Variance of additive genetic effect }\left(\mathrm{kg}^{2}\right)\end{array}$ & & & \\
\hline $\begin{array}{l}\text { Alta } \\
\text { Hight }\end{array}$ & $664.582,3064$ & $442.823,9371$ & $391.157,1383$ \\
\hline $\begin{array}{l}\text { Média } \\
\text { Average }\end{array}$ & & $340.308,1643$ & $271.406,4653$ \\
\hline $\begin{array}{l}\text { Baixa } \\
\text { Low }\end{array}$ & & & $243.226,0095$ \\
\hline $\begin{array}{l}\text { (Co)variância do efeito permanente de meio }\left(\mathrm{kg}^{2}\right) \\
\text { (Co)Variance of the permanent environment effect }\left(\mathrm{kg}^{2}\right)\end{array}$ & $197.364,7724$ & $280.772,7298$ & $157.408,3590$ \\
\hline $\begin{array}{l}\text { (Co)variância residual }\left(\mathrm{kg}^{2}\right) \\
\text { (Co)Variance of residual effect }\left(\mathrm{kg}^{2}\right)\end{array}$ & $973.626,0455$ & $735.571,9708$ & $556.439,6649$ \\
\hline
\end{tabular}

Tabela 3 - Estimativas de componentes de (co)variância genética aditiva, permanente de meio, interação reprodutor x rebanho e residual, para produção de leite ajustada a 305 dias e idade adulta, obtidas pelo modelo com interação

Table 3 - Genetic additive, environment uncorrelated and residual variance components for 305 days equivalent mature milk yield in a model with sire by herd interaction

\begin{tabular}{|c|c|c|c|}
\hline \multirow[t]{2}{*}{$\begin{array}{l}\text { Componente } \\
\text { Component }\end{array}$} & \multicolumn{3}{|c|}{$\begin{array}{l}\text { Classes de devios-padrão } \\
\text { Standard deviation class }\end{array}$} \\
\hline & $\begin{array}{l}\text { Alto } \\
\text { Hight }\end{array}$ & $\begin{array}{l}\text { Médio } \\
\text { Average }\end{array}$ & $\begin{array}{l}\text { Baixo } \\
\text { Low }\end{array}$ \\
\hline $\begin{array}{l}\text { (Co)variância genética aditiva }\left(\mathrm{kg}^{2}\right) \\
\text { (Co)Variance of additive genetic effect }\left(\mathrm{kg}^{2}\right)\end{array}$ & & & \\
\hline $\begin{array}{l}\text { Alta } \\
\text { Hight }\end{array}$ & $627.653,3682$ & $430.976,4123$ & $391.247,7542$ \\
\hline Média & & $331.780,3213$ & $268.597,9617$ \\
\hline $\begin{array}{l}\text { Average } \\
\text { Baixa }\end{array}$ & & & $243.885,0410$ \\
\hline $\begin{array}{l}\text { Low } \\
\text { (Co)variância do efeito permanente de meio }\left(\mathrm{kg}^{2}\right) \\
\text { (Co) Variance of permanent environment effect }\left(\mathrm{kg}^{2}\right)\end{array}$ & $166.475,2292$ & $259.975,0494$ & $137.172,0234$ \\
\hline $\begin{array}{l}\text { (Co)variância da interação reprodutor } \mathrm{x} \text { rebanho }\left(\mathrm{kg}^{2}\right) \\
\text { (Co) variance of the sire by herd interaction effect }\left(\mathrm{kg}^{2}\right)\end{array}$ & $72.454,7766$ & $31.212,2381$ & $25.712,0621$ \\
\hline $\begin{array}{l}\text { (Co)variância residual }\left(\mathrm{kg}^{2}\right) \\
(\text { Co }) \text { Variance residual effect }\left(\mathrm{kg}^{2}\right)\end{array}$ & $970.962,1089$ & $734.865,3633$ & $558.352,7181$ \\
\hline
\end{tabular}

quando a interação reprodutor $\mathrm{x}$ rebanho fosse considerada no modelo.

DE VEER e VAN VLECK (1987) encontraram correlações genéticas que variaram de 0,86 a 0,97 entre as classes de rebanhos, estratificadas de acordo com a média da produção de leite, para as classes de rebanho-ano-estação, em baixo, médio e alto níveis de produção. BOLDMAN e FREEMAN (1990) detectaram correlações genéticas, para produção de leite, que variaram de 0,90 a 1,02 entre os níveis de produção baixo, médio e alto. COSTA (1998) verificou correlações genéticas de 0,997 e 0,985 , para produções de leite e de gordura, respectivamente, entre as classes de baixo e alto desvios-padrão fenotípicos da produção de leite. TORRES (1998) observou correlações genéticas, para produção de leite, entre as classe de baixo, médio e alto desvios-padrão fenotípicos, que variaram de 0,92 a 0,97 . 
998 Rev. bras. zootec.

Tabela 4 - Estimativas de herdabilidades, correlações genéticas e proporções da variância fenotípica devido à variância do efeito permanente de meio $\left(C^{1}\right)$, ao efeito da interação reprodutor $x$ rebanho $\left(C^{2}\right)$ e ao efeito residual (e), para produção de leite ajustada para 305 dias e idade adulta

Table 4 - Estimates of heritability, genetic correlation and proportions of the phenotypic variance due to permanent environment $\left(C^{1}\right)$, sire by herd interaction $\left(C^{2}\right)$ and residual variance (e) estimates for 305 days mature equivalent milk yield for models with and without sire by herd interaction

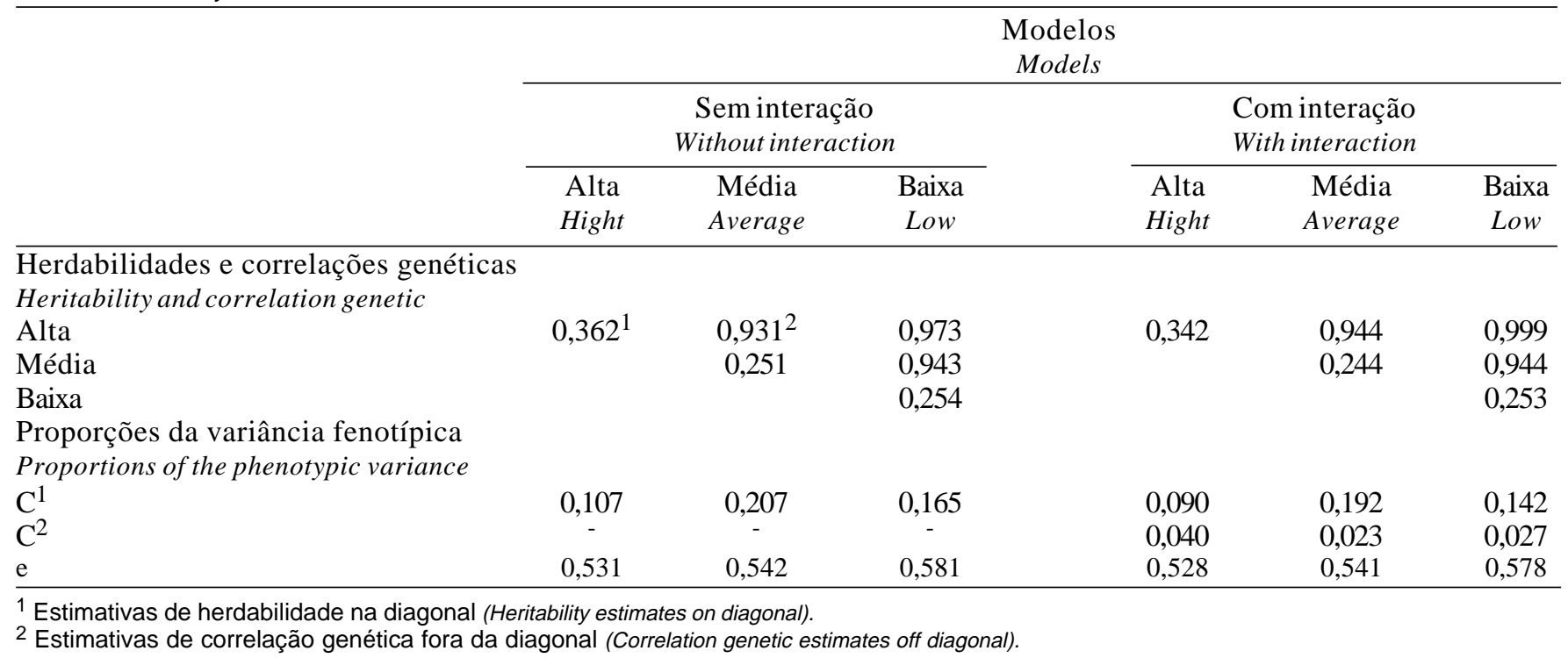

\section{Conclusões}

Com maiores estimativas de herdabilidades na classe de alto desvio-padrão fenotípico, conclui-se que grande parte da heterogeneidade de variância entre os rebanhos foi devida a fatores genéticos, razão pela qual, nesta situação, a interação reprodutor $\mathrm{x}$ rebanho seria pouco efetiva no controle da heterogeneidade de variância. Em avaliações genéticas dos animais, é importante identificar a presença de heterogeneidade de variância, bem como os fatores que a originaram para a devida correção, de forma a evitar vícios na avaliação genética de reprodutores de bovinos leiteiros.

\section{Agradecimento}

À Associação Brasileira de Criadores de Bovinos da Raça Holandesa e ao Centro Nacional de Pesquisa de Gado de Leite da EMBRAPA, pelo fornecimento dos dados utilizados nesta pesquisa.

\section{Referências Bibliográficas}

BANOS, G., SHOOK, G.E. 1990. Genotype by environment interaction and genetic correlations among parities for somatic cell count and milk yield. J. Dairy Sci., 73(9):2563-2573.

BERESKIN, B., LUSH, J.L. 1965. Genetic and environmental factors in dairy sire evaluation. III. Influence of environmental and others extraneouscorrelations among the daughters. J. Dairy Sci., 48(3):356-360.

BOLDMAN, K.G., FREEMAN, A.E. 1990. Adjustment for heterogeneity of variance by herd production level in dairy cow and sire evaluation. J. Dairy Sci., 73(2):503-512.

BOLDMAN, K.G., KRIESE, L.A., VAN VLECK, L.D. et al. 1995. A manual for use of MTDFREML: a set of programs to obtain estimates of variances and covariances (DRAFT). Lincoln: Department of Agriculture / Agriculture Research Service. $125 \mathrm{p}$.

COSTA, C.N. Genetic relationships for milk and fat yields between Brazilian and United States Holstein cattle populations. Ithaca (NY), 1998. 175p. Thesis (Doctor of Philosophy) - Cornell University, 1998.

COSTA, C.N. Interação genótipo x ambiente em gado de leite. In: SIMPÓSIO INTERNACIONAL DE GENÉTICA E MELHORAMENTO ANIMAL, 1, 1999, Viçosa. Anais...Viçosa: UFV, 1999. p.161-191.

DE VEER, J.C., VAN VLECK, L.D. 1987. Genetic parameters for first lactation milk yilelds at three levels of herd production. J. Dairy Sci., 70(7):1434-1441.

DICKERSON, G.E. 1962. Implication of genetic-environmental interaction in animal breeding. Anim. Prod., 4(1):47-63.

DODENHOFF, J., SWALVE, H.H. 1998. Heterogeneity of variances across regions of northern Germany and adjustment in genetic evaluation. Livest. Prod. Sci., 53(1):225-236.

DONG, M. C., MAO, I. L. 1990. Heterogeneity of (co)variance and heritability in different levels of intra-herd milk prodiction variance and of herd average. J. Anim. Sci., 73(3):843-851.

ENGEL, B., MEUWISSEN, T., DE JONG, G., BUIST, W. 1999. Prediction of breding values with a mixed model with heterogeneous variances for large-scale dairy data. J. Agric., Biolog. Environmental Statistics, 4(2):185-201.

FALCONER, D. S. 1989. Introduction to quantitative genetics. 2.ed. New York: Longman. 340p.

HILL, W.G., EDWARDS, M.R., AHMED, M.K.A. et al. 1983. Heritability of milk yield and composition at different levels and variability of production. Anim. Prod., 36(1):59-68.

MEYER, K. 1987. Estimates of variance due to sire $\mathrm{x}$ herd interactions and environmental covariances between paternal 
ARAÚJO et al.

half-sibs for first lactation dairy production. Livest. Prod. Anim. Sci., 17(1):95-115.

MRODE, R.A, SWANSON, G.J.T., SMITH, C. et al. Animal model estimates of sire-herd interactions for production traits for the major dairy breeds in the United Kingdom. In: WORLD CONGRESS ON GENETICS APPLIED TO LIVESTOCK PRODUCTION, 5., 1994, Ontario. Proccedings... Ontario, 1994. p.19-22.

NORMAN, H. D. 1974. Factors that should be considered in a national sire summary model. J. Dairy Sci., 57(7): 955-962.

PACKER, I.U. Interação genótipo-ambiente em animais. In: SEMINÁRIO DE BIOTECNOLOGIA AGRÍCOLA, 3, 1985, Piracicaba.Anais... Piracicaba: FEALQ, 1985.p.201-221.

RAO, C. R. 1973. Linear statistical inference and its aplications. 2.ed., New York: John Wiley e Sons. 552p.

SEARLE, S.R. 1966. Matrix algebrafor biological science. New York: John Wiley and Sons. 296p.

SHORT, T.H., BLAKE, R.W., QUAAS, R.L. et al. 1990. Heterogeneous within-herd variance: 1 - Genetic parameters for first and seond lactation milk yield of grade Hostein cows. J. Dairy Sci., 73(11):3312-3320.
STANTON, T.L., BLAKE, R.W., QUAAS, R.L. et al. 1991 Genotype by enviroment interaction for Holstein milk yield in Colombia, México and Porto Rico. J. Dairy Sci., 74(5):1700-1714.

TORRES, R.A. Efeito da heterogeneidade de variância na avaliação genética de bovinos da raça Holandesa no Brasil. Belo Horizonte: UFMG, 1998. 124 p. Tese (Doutorado em Ciência Animal) - Universidade Federal da Minas Gerais, 1998.

Recebido em: 06/09/00

Aceito em: 12/03/01 